\title{
ONE YEAR CLINICAL INVESTIGATION OF LABORATORY-FABRICATED AND CAD/CAM INLAY/ONLAY
}

\author{
Viktoria Petrova-Pashova ${ }^{1}$, Janet Kirilova ${ }^{1}$, Dimitar Kirov ${ }^{2}$ \\ 1) Department of Conservative Dentistry, Faculty ofDental Medicine, Medical \\ University, Sofia, Bulgaria. \\ 2) Department of Prosthetic Dentistry, Faculty of Dental Medicine, Medical \\ University, Sofia, Bulgaria.
}

\section{SUMMARY:}

Aim of the study:There are only a few studies available that deal with the clinical behaviour of different types of composite inlays. The aim of this study is to compare the clinical performance of three different groups of composite inlays.

Material and Methods:Twenty-five laboratory-fabricated composite inlays (Signum, Heraeus Kulzer), fifteen CAD/CAM inlays (Cerasmart, GC) with standard impression technique and $14 \mathrm{CAD} / \mathrm{CAM}$ inlays (Cerasmart, GC) with digital impression were placed in 43 patients by 2 experienced dentist. The first clinical evaluation was performed 1 year after placement of the restorations and used modified United States Public Health Services criteria.

Results: All of the indirect restorations were shown acceptable clinical results except one. Statistical analysis was performed with the One-way Anova test and Tukey HSD test between the groups. There was a significant difference between groups. Group 1 has shown a significant difference than Group 2 and 3.

Conclusion:It can be concluded that there is a significant difference in of clinical performance between laboratory and $\mathrm{CAD} / \mathrm{CAM}$ composite inlays. $\mathrm{CAD} / \mathrm{CAM}$ composite inlays were shown better result than laboratory-fabricated.

Keywords: CAD/CAM inlay/onlay, laboratory-fabricated inlay/onlay, clinical investigation

\section{INTRODUCTION}

Patients' demand for aesthetic restorations and the need to find alternatives to amalgam in the last years are the reasons for the increased use of resin-based composite and ceramic materials for posterior tooth restorations [1]. The composite materials have an elastic modulus similar to the dental structures and high potential to bond with enamel and dentin. This is one of the reasons why they are more preferable to ceramic materials.

There are two different types of composite restorations: direct - the polymerization of the material is in the mouth, and indirect - the fabrication of the restorations is outside of the mouth. As the indirect restorations provide more precise marginal integrity, ideal proximal contacts, wear resistance, reduced polymerization shrinkage, and optimal aesthetics, they are preferred over the direct ones in cases of severe damage posterior vital teeth. They have lower failure rates than direct composite restorations and they prove to be an excellent choice of material for vital posterior teeth [2]. However, indirect restorations have two major disadvantages - their price is higher and their fabrication - more time-consuming.

Nowadays materials for indirect restorations could be divided into two groups: for laboratory and for CAD/ CAM application. All of them could be named hybrid ceramics, but their composition is, in fact, closer to direct composites. Indirect composite materials are characterized by filler content possibly exceeding $70 \%$ by volume, which provides improved fractural strength [3].

The indirect laboratory composites currently available are second-generation laboratory composite systems. Signum ceramic (Heraeus Kulzer) is a tooth-colored indirect resin composite with the advantages of both ceramic materials and resin composites. This hybrid ceramics contains a high percentage of inorganic filler particles (73 $\mathrm{wt} \%$ ) and multi-functional (meth)acrylic acid esters (27 wt $\%)$.

Composite resin-based inlays could also be fabricated with CAD/CAM technology. This technology was introduced during the 1980s from Duret [4] and it has rapidly gained popularity. Cerasmart (GC) is one of the latest composite blocks and it consists of $71 \mathrm{wt} \%$ of inorganic filler particles and organic polymer from Bis-MEPP, UDMA, DMA. The system exhibits superior physical and aesthetic properties.

Many in vitro studies on the subject of indirect composite inlays have been published, but there are few concerning the clinical behaviour of new generation materials for indirect technique.

The aim of this study was to compare the clinical performance of three different types of composite inlays according to the modified USPHS criteria. The null hypothesis we were testing was that the indirect CAD/CAM inlays with digital impression technique show better results than the other two groups. 


\section{MATERIAL AND METHODS:}

All patients recruited for the study were fully informed of the nature of the study and the need for their long-term availability. Each patient signed a written consent form before being enrolled in the study. Each patient enrolled in the study had at least one two-surface (mesioocclusal or disto-occlusal) or three-surface (mesial-occlusal-distal) carious lesion or defective restoration to be restored on maxillary or mandibular premolars or molars. Each lesion or defective restoration exhibited sufficient size to extend at least one-half the intercuspal width of the tooth. All restored teeth were in functional occlusion. Exclusion criteria included nonvital teeth, sensitive teeth, teeth with previous endodontic treatment, patients with the significant untreated dental disease (including periodontitis and rampant caries) and bad oral hygiene.

During the period December 2017 to August 2018, forty-three patients, randomly divided into three groups, received 54 composite inlays. Group A included 25 composite inlays of Signumceramis (Heraeus Kulzer), Group B - 15 composite inlays of Cerasmart (GC) with standard impression technique and Group $\mathrm{C}-14$ composite inlays of Cerasmart (GC) with digital impression.

\section{Cavity preparation}

Inlay cavity preparation consisted of butt joint margins without bevels. All walls were tapered 8 to 12 degrees from the pulpal floor to the cave surface margin. Liner (Calcimol LC, Voco) and base (Fuji IILC, GC) were used in deep cavities. The flare of the proximal boxes conformed to standard criteria for an inlay with the proximal margins exposed for convenience in finishing.Before the impression, immediate dentin sealing of the cavities was performed (OptiBond Solo Plus, Kerr).

\section{Impression technique and inlay fabrication Group A}

After cavity preparation, a two-stage impression was taken using double viscosity A-silicone (Variotime, Heraeus Kulzer)in a stock metal tray. The impressions were poured with type IV dental stone (Octarock, HeraeusKulzer). After that, the cavities were isolated with isolating gel (Signum insulating gel, Heraeus Kulzer). All of the laboratory in- lays were made with a horizontal layering technique using a composite material (Signumceramis, Heraeus Kulzer). Three layers were adapted for each inlay. Every layer was polymerized for $6 \mathrm{sec}$ and finally for $90 \mathrm{sec}$ with a light curing unit (HiLightpower 3D,Heraeus Kulzer).

\section{Group B}

After cavity preparation, a two-stage impression was taken using double viscosity A-silicone (Variotime, Heraeus Kulzer)in a stock metal tray. The impressions were poured with type IV dental stone (Octarock,HeraeusKulzer). The surface of models was scanned (Evolution Zfx, Zimmer Biomet) and digital model was calculated. Then the restorations were milled with a digital preset spacer for the cement-gap of $50 \mu \mathrm{m}$ (Zfx in house 5x, Zimmer Biomet).

\section{Group C}

For group $\mathrm{C}$ after cavity preparation, a digital impression was taken using an intraoral scanner (Intra scan Zfx, Zimmer Biomet) and digital model was calculated. Then the restorations were milled with a digital preset spacer for the cement-gap of $50 \mu \mathrm{m}$ ( $\mathrm{Zfx}$ in house $5 \mathrm{x}$, Zimmer Biomet).

\section{Cementation}

The inner surfaces of the inlays were treated with $\mathrm{Al}_{2} \mathrm{O}_{3} 50 \mu \mathrm{m}$ and silanized(Silan, Cerkamed)prior to cementation. After isolation of the operative field with a rubber dam, the cavity surfaces were treated with $\mathrm{H}_{2} \mathrm{O}_{2}$ and alcohol and after that, a self-adhesive dual cured composite cement (i-Cem, Kulzer) was applied to it. With soft pressure, the inlay was seated completely and after light curing, for 1-2 sec the excess cement was removed. The resin composite luting material was finally light cured for 30 seconds from each side.

\section{Evaluation of inlays}

Two experienced dentists rated the restorations with mirror and probe after insertion (baseline evaluation) and at 1 year. The criteria listed in Table 1 were assessed using modified USPHS criteria for the direct evaluation of the adhesive technique. This evaluation resulted in ordinary structured data for the outcome variables: alpha = excellent result; bravo = acceptable result; charlie = replacement of the restoration for prevention [5].

Table 1. Modified United States Public Health Service evaluation criteria.

\begin{tabular}{|l|l|l|l|}
\hline & Alfa & Bravo & Charlie \\
\hline Colour match & $\begin{array}{l}\text { Restoration matches adjacent } \\
\text { tooth structure in colour and } \\
\text { translucency }\end{array}$ & $\begin{array}{l}\text { Mismatch is within an } \\
\text { acceptable range of tooth } \\
\text { colour and translucency }\end{array}$ & $\begin{array}{l}\text { Mismatch is outside of } \\
\text { acceptable range }\end{array}$ \\
\hline Marginal discoloration & No discoloration evident & $\begin{array}{l}\text { Slight staining can be } \\
\text { polished away }\end{array}$ & $\begin{array}{l}\text { Obvious staining, cannot be } \\
\text { polished away }\end{array}$ \\
\hline Anatomic form & Continuous & $\begin{array}{l}\text { Slight discontinuity, } \\
\text { clinically acceptable }\end{array}$ & Discontinuous, failure \\
\hline Marginal adaptation & $\begin{array}{l}\text { Closely adapted, } \\
\text { no visible crevice }\end{array}$ & $\begin{array}{l}\text { Visible crevice, explorer will } \\
\text { penetrate }\end{array}$ & $\begin{array}{l}\text { Crevice in which dentin is } \\
\text { exposed }\end{array}$ \\
\hline Secondary caries & No evidence of caries & Caries is evident \\
\hline
\end{tabular}




\begin{tabular}{|l|l|l|l|}
\hline Proximal contact & Physiological & Far to weak & Gingival trauma \\
\hline Surface texture & Smooth surface & Slightly rough or pitted & $\begin{array}{l}\text { Surface deeply pitted, } \\
\text { irregular grooves }\end{array}$ \\
\hline $\begin{array}{l}\text { Integrity of } \\
\text { restorations }\end{array}$ & $\begin{array}{l}\text { No splits, cracks, } \\
\text { roughness, fractures }\end{array}$ & Loss of part of restoration & Loss of restoration \\
\hline
\end{tabular}

Statistical analysis was performed using one way ANOVA with a post hoc test. A $P$ value less than 0.05 was considered statistically significant. SPSS 22.0 software (SPSS, Inc., Chicago, IL, USA)was used to analyze the data.

\section{RESULTS:}

In total, 44 patients with restorations could be reexamined from December 2018 to August 2019. Twenty patients with 25 laboratory-fabricated inlay restorations and 24 patients with $29 \mathrm{CAD} / \mathrm{CAM}$ composite restorations agreed to participate in the study.

After statistical analyses, it could be concluded that there is a significant difference between laboratory-fabricated and CAD/CAM inlays. Descriptive data and correlations are in Table 2.

Table 2. Descriptive statistics of the study groups.

\begin{tabular}{|l|c|c|c|c|}
\hline Treatment $\rightarrow$ & A & B & C & Pooled Total \\
\hline observations N & 200 & 120 & 112 & 432 \\
\hline sum $\Sigma x i$ & 219.0000 & 122.0000 & 114.0000 & 455.0000 \\
\hline mean $^{-} x$ & 1.0950 & 1.0167 & 1.0179 & 1.0532 \\
\hline sum of squares $\Sigma x 2 i$ & 257.0000 & 126.0000 & 120.0000 & 503.0000 \\
\hline sample variance s2 & 0.0864 & 0.0165 & 0.0357 & 0.0552 \\
\hline sample std. dev. $s$ & 0.2940 & 0.1286 & 0.1890 & 0.2349 \\
\hline std. dev. of mean $S^{-} x$ & 0.0208 & 0.0117 & 0.0179 & 0.0113 \\
\hline
\end{tabular}

One-way analysis of variance was used to test the difference between the means of several subgroups of a variable (multiple testing). Table 3 displays the summary for the ANOVA.

Table 3. One-way ANOVA of the study groups.

\begin{tabular}{|c|c|c|c|c|c|}
\hline Source & $\begin{array}{c}\text { sum of squares } \\
\text { SS }\end{array}$ & $\begin{array}{c}\text { degrees of } \\
\text { freedom v }\end{array}$ & $\begin{array}{c}\text { mean square } \\
\text { MS }\end{array}$ & F statistic & p-value \\
\hline Treatment & 0.6495 & 2 & 0.3248 & 6.0244 & 0.0026 \\
\hline Error & 23.1260 & 429 & 0.0539 & & \\
\hline Total & 23.7755 & 431 & & & \\
\hline
\end{tabular}

The results of the ANOVA (fig. 1) allowed rejecting the null hypothesis $\mathrm{H}_{0}$ and supporting the conclusion that there is a statistically significant difference between the three groups. The p-value corresponding to the F-statistic of one-way ANOVA is lower than 0.05, suggesting that one or more treatments are significantly different. The Tukey HSD test, multiple comparison tests follows (tabl. 4).

Table 4.Tukey HSD results.

\begin{tabular}{|c|c|c|c|}
\hline treatments pair & Tukey HSD Q statistic & Tukey HSD p-value & Tukey HSD inferfence \\
\hline A vs B & 4,1321 & 0,0102263 & $* \mathrm{p}<0.05$ \\
\hline A vs C & 3,9814 & 0,0140915 & $* \mathrm{p}<0.05$ \\
\hline B vs C & 0,0552 & 0,8999947 & insignificant \\
\hline
\end{tabular}


Fig. 1.Graphical representation of statistical analysis (One-way ANOVA) of the mean.

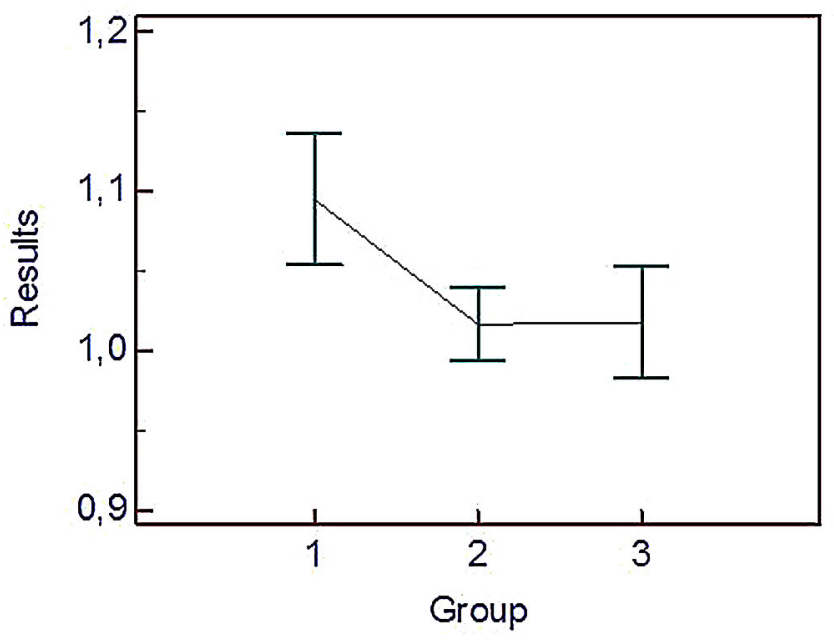

The results conclude that groups A and B are different, whereas groups B and $\mathrm{C}$ are not different and groups $\mathrm{A}$ and $\mathrm{C}$ are also different.

\section{DISCUSSION:}

In many in vivo studies, USPHS criteria were used for the clinical evaluation of tooth-colored restorations in posterior teeth $[6,7]$. To ensure comparability of the results of the current study with other studies, in this study, laboratory-fabricated and CAD/CAM composite inlays were also assessed using USPHS criteria.

The composite resin-based inlays were evaluated for a period of one year in this study. Some clinical studies using USPHS criteria had the same period of observations $[8,9]$ while others had longer observation periods $[10,11]$.

In their study, Barone and others used different reexamination interval of 3 years, but the same examination criteria [12]. They reported a failure rate of $2.6 \%$ for the tested composite inlays (Signum, Heraeus Kulzer). In this study, we investigated the clinical performance of laboratory-fabricated inlays (Signum, Heraeus Kulzer) and also CAD/CAM inlays (Cerasmart, GC). We found that a failure rate of laboratory-fabricated (Signum, Heraeus Kulzer) and $\mathrm{CAD} / \mathrm{CAM}$ with standard impression technique inlays is 0 $\%$ for 1 year and the failure rate of CAD/CAM inlays with digital impression was $7 \%$ for 1 year.

Derchi and others evaluated 99 composite inlays (Signum, Heraeus Kulzer) cemented with three-step bonding system and composite resin luting cement over a period up to 12 years and found a survival rate of $88 \%$. According to their study adhesively bonded indirect composite resin inlays showed acceptable long-term clinical re- sults in terms of function, but surface and margin characteristics changed over time [13].

Colour matching for CAD/CAM restorations may be considered problematic owing to the monochromatic nature of the mill blocks. Fasbinder and others conducted a study to evaluate the clinical performance of a resin-based composite (Paradigm, 3M ESPE) for CAD/CAM inlays and porcelain inlays of Vita Mark II for a period of three years [14]. Initial colour match for both materials was rated very well and was maintained better by the resin-based composite inlays at three years. Tooth colour match of the porcelain inlays decreased by the six-month recall but then remained unchanged at the three-year recall. In this study, we investigated a new type of resin-based composite block (Cerasmart, GC).

Marginal adaptation is one of the most important factors for longevity of indirect restorations. It has been suggested that an increase in margin gap size may lead to degradation of the adhesive bond, in turn resulting in microleakage and recurrent caries. However, there is no evidence about it. Fasbinder and others reported an equivalent initially marginal adaptation of composite and porcelain inlays [14]. Manhart and others evaluated ceramic and composite inlay for two years [15]. They reported many Bravo scores for "marginal integrity" and "anatomic form at the marginal step". This could be due to resin cement wearing in the luting gap, which is less wear resistant than ceramics and post-cured composite inlays. In this study, all of the materials were resin-based composites with a similar composition. This could lead to similar resin cement wearing. For a period of a year, all of the restorations of this study had a score "Alfa" for "marginal integrity".

In this study, we showed the results after one year and they are the CAD/CAM inlays had better results than laboratory-fabricated. Therefore, a longer observation period is indicated for substantiating the clinical performance of different types of composite inlays.

\section{CONCLUSION:}

Within the limits defined in the experimental design, it can be concluded that there is a significant difference between the three groups of composite inlays and the null hypothesis was rejected. CAD/CAM inlays shown better result than laboratory-fabricated ones. There is no statistically significant difference between the two groups of CAD/ CAM inlays.

\section{Acknowledgements}

The study was conducted with the financial support of the Council of Medical Science, Medical University Sofia, Bulgaria 
REFERENCES:

1. Collares K, Corrêa MB, Laske M, Kramer E, Reiss B, Moraes RR, et al. A practice-based research network on the survival of ceramic inlay/onlay restorations. Dent Mater. 2016 May;32(5): 687-94. [PubMed] [Crossref]

2. Morimoto S, Rebello de Sampaio FB, Braga MM, Sesma N, Özcan M. Survival Rateof Resin and Ceramic Inlays and Overlays: A Systematic Review and Meta-analysis. J Dent Res. 2016 Aug;95(9):985-94.[PubMed] [Crossref]

3. Goujat A, Abouelleil H, Colon P, Jeannin C, Pradelle N, Seux D, et al. Mechanical properties and internal fit of 4 CAD-CAM block materials. $J$ Prosthet Dent. 2018 Mar;119(3):384389. [PubMed] [Crossref]

4. Blatz MB, Conejo J. The Current State of Chairside Digital Dentistry and Materials. Dent Clin North Am. 2019 Apr;63(2):175-197. [PubMed] [Crossref]

5. Moncada G, Silva F, Angel P, Oliveira OB Jr, Fresno MC, Cisternas P, et al. Evaluation of dental restorations: a comparative study between clinical and digital photographic assessments.
Oper Dent. 2014 Mar-Apr;39(2):45-56. [PubMed] [Crossref]

6. Otto T, De Nisco S. ComputerAided Direct Ceramic Restorations: A 10-Year Prospective Clinical Study of Cerec CAD/CAM Inlays and Onlays. Int J Prosthodont.2002 Mar-Apr;15(2): 122-8. [PubMed]

7. Wassell RW, Walls AW, McCabe JF. Direct composite inlays versus conventional composite restorations: 5year follow-up. J Dent. 2000 Aug;28(6): 375-82. [PubMed] [Crossref]

8. Bessing C, Lundqvist P. A 1-year clinical examination of indirect composite resin inlays: a preliminary report. Quintessence Int. 1991 Feb;22(2):1537. [PubMed]

9. Scheibenbogen A, Manhart J, Kunzelmann KH, Hickel R. One-year clinical evaluation of composite and ceramic inlays in posterior teeth. $J$ Prosthet Dent. 1998 Oct;80(4):410-6. [PubMed] [Crossref]

10. Molin MK, Karlsson SL. A randomized 5-year clinical evaluation of 3 ceramic inlay systems. Int $J$ Prosthodont. 2000 May-Jun;13(3):194-
200. [PubMed]

11. Otto T, Schneider D. Long-term clinical results of chairside Cerec CAD/ CAM inlays and onlays: a case series. Int J Prosthodont. 2008 Jan-Feb; 21(1):53-9. [PubMed]

12. Barone A, Derchi G, Rossi A, Marconcini S, Covani U. Longitudinal clinical evaluation of bonded composite inlays: A 3-year study. Quintessence Int. 2008 Jan;39(1):65-71. [PubMed]

13. Derchi G, Marchio V, Borgia V, Özcan M, Giuca MR, Barone A. Twelveyear longitudinal clinical evaluation of bonded indirect composite resin inlays. Quintessence Int. 2019; 50(6):448-454.

[PubMed] [Crossref]

14. Fasbinder DJ, Dennison JB, Heys DR, Lampe K. The clinical performance of CAD/CAM-generated composite inlays. J Am Dent Assoc. 2005 Dec; 136:1714-23. [PubMed] [Crossref]

15. Manhart J, ScheibenbogenFuchsbrunner A, Chen HY, Hickel R. A 2-year clinical study of composite and ceramic inlays. Clin Oral Investig. 2000 Dec;4(4):192-8. [PubMed] [Crossref]

Please cite this article as: Petrova-Pashova V, Kirilova J, Kirov D. One year clinical investigation of laboratory-fabricated and CAD/CAM inlay/onlay. J of IMAB. 2020 Jul-Sep;26(3):3336-3340.

DOI: https://doi.org/10.5272/jimab.2020263.3336

Received: 01/10/2019; Published online: 28/09/2020

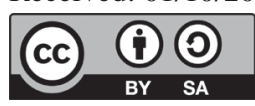

\author{
Author contact information: \\ Janet Kirilova, Assosiate Professor, DDS, PhD \\ Department of Conservative Dentistry, Faculty of Dental Medicine, Medical \\ University - Sofia, \\ 1, St. GeorgiSofiiski Str., 1431 Sofia, Bulgaria. \\ E-mail: janetkirilova@gmail.com
}

